\title{
Camostate (FOY-305) improves the therapeutic effect of peritoneal lavage on taurocholate induced pancreatitis
}

\author{
U Leonhardt, F Seidensticker, M Fussek, F Stöckmann, W Creutzfeldt
}

\begin{abstract}
The effect of peritoneal lavage with the addition of camostate to the lavage fluid on the outcome of taurocholate pancreatitis in rats was studied. Camostate is a low molecular weight protease inhibitor which has been developed recently. Peritoneal lavage was performed for $\mathbf{1 2}$ hours and camostate was added to the lavage fluid in five concentrations. At $0 \cdot 1$ $\mathrm{mg} / \mathrm{ml}$ the survival rate increased significantly (11 of $20 v$ controls 4 of 20, p<0.05); the maximal effect was observed at $0.2 \mathrm{mg} / \mathrm{ml}$, and no effect was seen at 0.01 and $0.05 \mathrm{mg} / \mathrm{ml}$. Adverse effects occurred at $0.5 \mathrm{mg} / \mathrm{ml}$. The addition of $0.1 \mathrm{mg} / \mathrm{ml}$ camostate significantly reduced the acidosis in arterial blood: mean (SD) pH $7.30(0.035) v$ controls $7.23(0.054)$ $(n=9, p<0.01)$ and arterial base excess: -15.4 $(1.26) \mathrm{mmol} / \mathrm{l} v$ controls: $-17.4(2.51) \mathrm{mmol} / \mathrm{l}$ $(n=9, p<0.05)$. There was no difference, however, in plasma amylase activity and in the histological degree of specific tissue damage to the pancreas. A combination of intravenous camostate and lavage with the addition of camostate to the lavage fluid yielded a significantly improved survival compared with treatment with intravenous camostate alone (10 out of 16 animals $v$ intravenous camostate alone, two out of $16, p>0.01)$. We conclude that lavage with camostate significantly improves the prognosis of severe necrotising pancreatitis in rats.
\end{abstract}

Peritoneal lavage is known to improve survival in experimental haemorrhagic pancreatitis in several species.' Although its benefit for humans has not been proved,' peritoneal lavage without the addition of protease inhibitors is a therapeutic regimen for severe acute pancreatitis ${ }^{2}$ and is routinely performed in some European centres. ${ }^{3}$ Intravenous or subcutaneous injection of the recently developed synthetic protease inhibitors camostate and gabexate mesilate has been tested in several forms of acute experimental pancreatitis. ${ }^{34}$ The combination of systemic application of

Department of Medicine, Division of Gastroenterology and Endocrinology, University of Göttingen, Göttingen, Germany U Leonhardt F Seidensticker M Fussek F Stöckmann W Creutzfeldt Correspondence to: U Leonhardt, Medizinische Universitätsklinik Göttingen, Robert-Koch Str 40, D-3400 Göttingen, Germany. Accepted for publication 24 October 1989
Addition of camostate to the lavage fluid in variou

$0.05 \mathrm{mg} / \mathrm{ml}$ camostate: 4/12, controls: $2 / 12$

$0 \cdot 1 \mathrm{mg} / \mathrm{ml}$ camostate: $11 / 20$, controls: $4 / 20$

$0.2 \mathrm{mg} / \mathrm{ml}$ camostate: $8 / 16$, controls: $2 / 16$

Control rats without any specific treatment: $1 / 18$

Comparison of intravenous camostate with peritoneal lavage Intravenous camostate alone

Intravenous camostate plus lavage without camostate

Intravenous camostate plus lavage with camostate camostate and peritoneal lavage has not been investigated, however. The theoretical advantage of camostate is its low molecular weight (494.5), which allows penetration into the intracellular space. ${ }^{+}$We evaluated the effect of peritoneal lavage with camostate added to the lavage fluid on the outcome of taurocholate induced acute pancreatitis in rats.

\section{Methods}

PERITONEAL LAVAGE WITH CAMOSTATE

After anaesthesia with xylazine $12 \mathrm{mg} / \mathrm{kg}$ intramuscularly (Bayer Leverkusen, Germany) and ketamine hydrochloride $80 \mathrm{mg} / \mathrm{kg}$ intramuscularly (Parke-Davis, Berlin, Germany) the jugular vein was cannulated in male Wistar rats (weight 180-220 g, from Mus Rattus, Brunnthal, Germany). The outlet of the catheter was put through the skin at the neck and was closed by a stopper. The animals regained consciousness shortly afterwards. After an overnight fast pancreatitis was induced under ether anaesthesia by median laparotomy and retrograde injection of $0.6 \mathrm{ml}$ of a $0.1 \mathrm{~mol} / \mathrm{l}(5 \%)$ sodium taurocholate solution (Serva, Heidelberg, Germany) into the pancreatic duct as previously described. ${ }^{+}$For peritoneal lavage, a polyethylene catheter (12 cm, model PP 100, Portex, London, UK) with six lateral outlets was inserted into a small incision at the neck and placed into the right abdominal cavity; $15 \mathrm{ml}$ of lavage fluid was then injected. The catheter was blocked for 15 minutes and then fluid was allowed to flow out for 15 minutes. Thus each lavage procedure lasted 30 minutes, and lavage was performed 24 times - that is, for 12 hours. Volume input and output were continuously monitored. The lavage fluid consisted of isotonic $\mathrm{NaCl}$ solution (154 $\mathrm{mmol} / \mathrm{l})$ with $\mathrm{KCl}(4 \mathrm{mmol} / \mathrm{l})$ with or without camostate at various concentrations: $0.01,0.05$, $0 \cdot 1,0 \cdot 2$, and $0.5 \mathrm{mg} / \mathrm{ml}$. Camostate was a gift of Schwarz Pharma GmbH (Monheim, Germany). The treatment (lavage, infusions, injections) started seven to nine minutes after the induction of pancreatitis. All rats received an albumin infusion (10\% albumin solution, Humanalbumin DRK Niedersachsen, Springe, Germany) simultaneously with the lavage for protein substitution. All animals were kept in single cages, had free access to water, and, after two days, to solid food. Buprenorphine $(0 \cdot 15 \mathrm{mg} / \mathrm{kg})$ was applied subcutaneously at 10 hour intervals for the 72 hour observation period to all rats in this study. The analgesic regimen has been shown not to influence the course of taurocholate pancreatitis in rats. 
INTRAVENOUS CAMOSTATE

To compare the additional effect of peritoneal lavage and intravenous administration of camostate, three groups of 16 rats each received the following: (i) intravenous camostate $(2.5 \mathrm{mg} / \mathrm{kg}$ per hour), but no lavage; (ii) lavage without the addition of camostate to the lavage fluid $(0 \cdot 1 \mathrm{mg} /$ $\mathrm{ml})$ plus intravenous camostate $(2.5 \mathrm{mg} / \mathrm{kg}$ per hour); (iii) lavage with camostate $(0 \cdot 1 \mathrm{mg} / \mathrm{ml})$ plus intravenous camostate $(2.5 \mathrm{mg} / \mathrm{kg}$ per hour).

In survival experiments the survival rates after the 72 hours observation period were compared by the $\chi^{2}$ test.

\section{ASSAYS AND CALCULATIONS}

For histology and for biochemical measurements rats were sacrificed 12 hours after the induction of pancreatitis and lavage with or without $0 \cdot 1$ $\mathrm{mg} / \mathrm{ml}$ camostate. Arterial blood was collected into heparinised syringes from the aorta after general anaesthesia and a second laparotomy. Blood $\mathrm{pH}$, base excess, and standard bicarbonate were quantified with an Acid-Base Laboratory 330 (Radiometer, Copenhagen, Denmark). Haemoglobin was determined with an OSM 3 Hemoximeter (Radiometer, Copenhagen, Denmark).

Amylase activity in plasma was quantified colorimetrically $^{6}$ using a commercial kit (Phadebas Amylase Test, Pharmacia Diagnostics AG, Uppsala, Sweden).

Pancreatic tissue for histology was fixed in formalin, embedded in paraplast, and $4 \mu \mathrm{m}$ slices were stained with haematoxylin and eosin. Examination by light microscopy was performed blind as to whether the section was from the
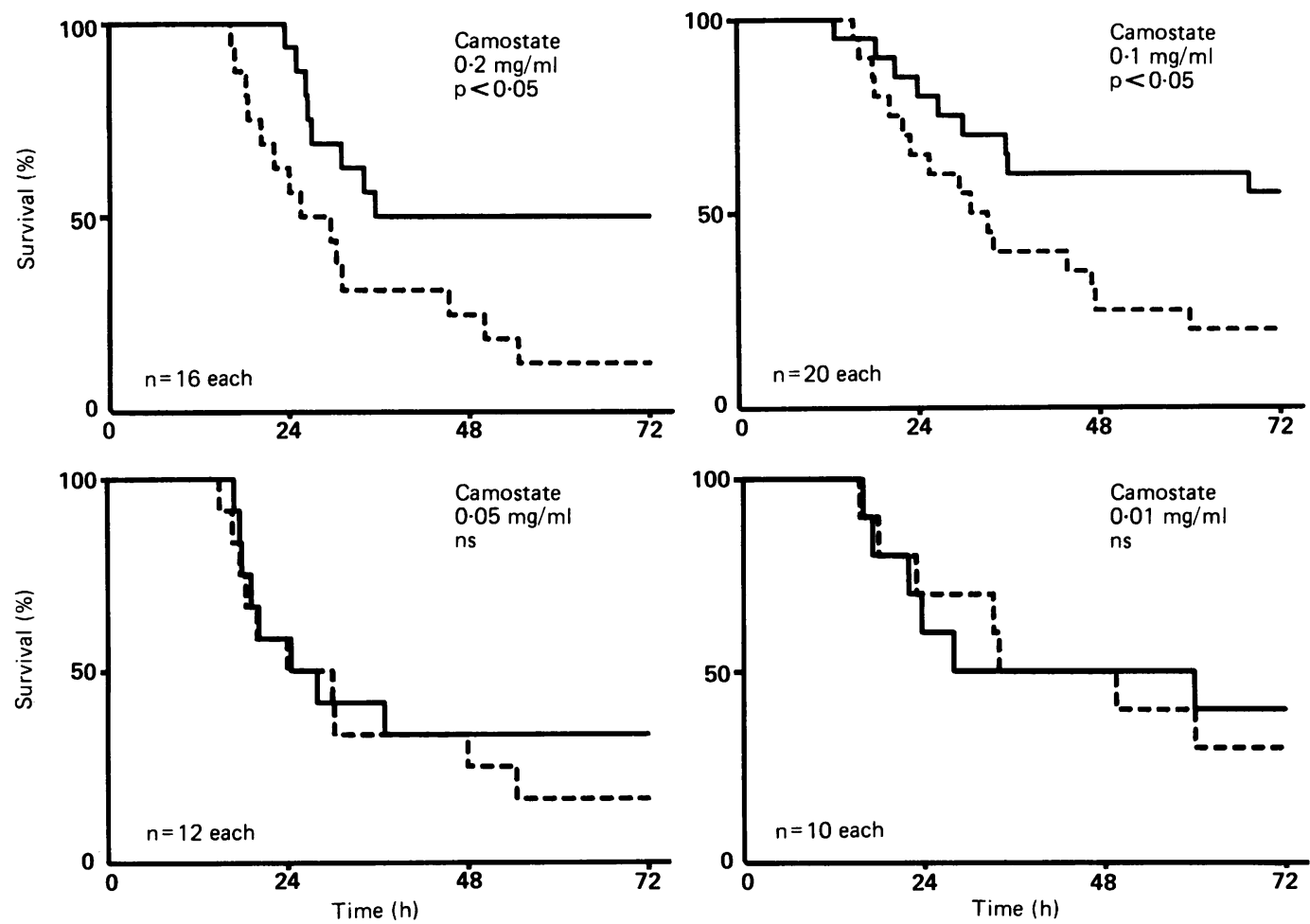

treatment or the control group. The extents of necrosis, oedema, haemorrhage, leucocyte infiltration, and vacuolisation of acinar cells were used as histological parameters for grading the specific tissue damage to the pancreas. ${ }^{4}$

The unpaired and two tailed $t$ test was used for comparison of biochemical data.

\section{Results}

FEASIBILITY OF THE LAVAGE PROTOCOL

The regimen for the lavage of blocking the catheter for 15 minutes after administering the lavage fluid and allowing a 15 minute outflow period was feasible: 226 animals received peritoneal lavage, and only two animals had to be excluded from the study because the input and output volumes of lavage fluid differed (one animal in a camostate treated group and one in a control group).

\section{EFFECT OF CAMOSTATE CONCENTRATION ON THE} SURVIVAL RATE

Camostate added to the lavage fluid at 0.01 and $0.05 \mathrm{mg} / \mathrm{ml}$ did not show a beneficial effect on the survival rate compared with the effect of lavage alone $(0.01 \mathrm{mg} / \mathrm{ml}$ : four out of 10 animals survived $v$ three out of 10 control animals; 0.05 $\mathrm{mg} / \mathrm{ml}$ : four out of 12 animals survived $v$ two out of 12 control animals; Fig 1, Table I). A concentration of $0.1 \mathrm{mg} / \mathrm{ml}$ yielded a significantly improved survival rate (11 out of 20 , four out of 20 controls; Fig 1, p <0.05). A concentration of $0.2 \mathrm{mg} / \mathrm{ml}$ showed similar results (survival rate: eight out of 16 animals $v$ two out of 16 controls). During lavage with $0.5 \mathrm{mg} / \mathrm{ml}$ camostate the

Figure 1: The effect of camostate in the lavage fluid (solid lines) on the survival time. At concentrations of $0 \cdot 01 \mathrm{mg} / \mathrm{ml}(\mathrm{n}=10)$ and $0.05 \mathrm{mg} / \mathrm{ml}(\mathrm{n}=12)$ the effect was not significant with concentration of $0.1 \mathrm{mg} / \mathrm{ml}(\mathrm{n}=20)$ and $0.2 \mathrm{mg} / \mathrm{ml}(\mathrm{n}=16)$ the survival was significantly improved $(p<0.05)$. Lavage was performed for the first 12 hours after pancreatitis was induced with taurocholate in rats. In control experiments (dotted lines) peritoneal lavage was performed without camostate. 
TABLE II Effect of lavage with the addition of camostate $(0 \cdot 1$ $\mathrm{mg} / \mathrm{ml}$ ) to lavage fluid on arterial blood gases, amylase activity in plasma, and histological degree of pancreatitis. The grading of the organ damage was quantified using a scale previously described. ${ }^{4}$ After induction of pancreatitis and subsequent peritoneal lavage for 12 hours, nine animals were sacrificed in each group. Values are mean $(S D)$

\begin{tabular}{|c|c|c|c|}
\hline & Lavage & $\begin{array}{l}\text { Lavage plus } \\
\text { camostate }\end{array}$ & \\
\hline $\begin{array}{l}\text { Arterial blood: } \\
\mathrm{pH} \\
\text { Base excess }(\mathrm{mmol} / \mathrm{l}) \\
\mathrm{PO}_{2}(\mathrm{kPa})\end{array}$ & $\begin{array}{c}7 \cdot 23(0 \cdot 054) \\
-17 \cdot 4(2 \cdot 51) \\
16 \cdot 4(1 \cdot 8)\end{array}$ & $\begin{array}{c}7 \cdot 30(0.035) \\
-15 \cdot 4(1 \cdot 26) \\
15 \cdot 9(1.0)\end{array}$ & $\begin{array}{l}\mathrm{p}<0.01 \\
\mathrm{p}<0.05\end{array}$ \\
\hline $\begin{array}{l}\text { Plasma: } \\
\text { Haemoglobin (g/dl) } \\
\text { Amylase (U/l) }\end{array}$ & $\begin{array}{r}13 \cdot 7(1 \cdot 5) \\
6640(1810)\end{array}$ & $\begin{array}{r}12 \cdot 9(2 \cdot 6) \\
7060(3010)\end{array}$ & \\
\hline $\begin{array}{l}\text { Histological gradings: } \\
\text { Necrosis } \\
\text { Vacuoles } \\
\text { Inflammation }\end{array}$ & $\begin{array}{l}2-3 \\
3 \\
1-2\end{array}$ & $\begin{array}{l}2 \\
3 \\
2\end{array}$ & \\
\hline
\end{tabular}

animals were agitated and developed cramps, making a regular lavage pattern impossible. This experiment was repeated twice, but the adverse effects of camostate were persistent. Only one of 18 control rats with taurocholate pancreatitis and no specific treatment (no camostate, no lavage, no intravenous fluid) survived the 72 hour observation period (Fig 2, Table I).

COMBINATION OF INTRAVENOUS CAMOSTATE AND PERITONEAL LAVAGE

A combination of treatment with intravenous camostate and the addition of camostate to lavage fluid resulted in the highest survival rate in this study (Fig $3 ; 10$ out of 16 animals $v$ intravenous camostate alone two out of $16, p>0 \cdot 01$ ). Lavage alone without the addition of camostate to the lavage fluid was also significantly better than intravenous camostate (seven out of 16 animals $v$ intravenous camostate alone two out of 16 , $\mathrm{p}>0.05)$.

\section{EFFECT OF LAVAGE WITH CAMOSTATE ON} BIOCHEMICAL PARAMETERS

The acidosis in arterial blood was significantly reduced by the addition of camostate to the lavage fluid when compared with the effect of lavage without camostate. No difference was seen in arterial $\mathrm{PO}_{2}$ and haemoglobin concentra-

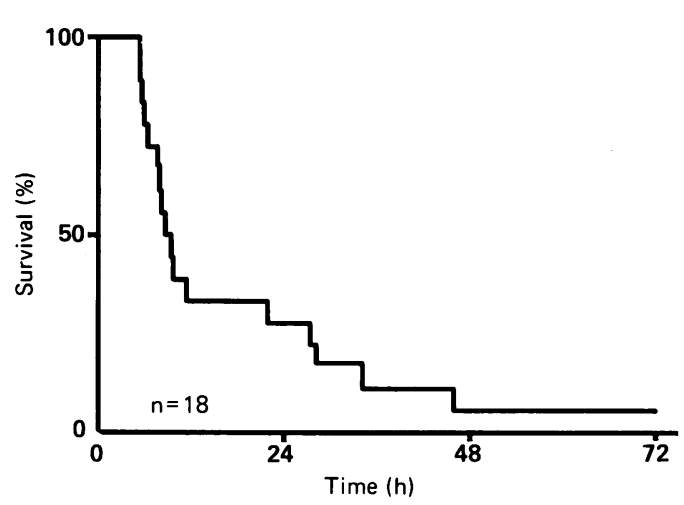

Figure 2: Survival rate in a control experiment without any specific treatment (no camostate, no lavage, no intravenous fluid). Pancreatitis was induced by injection of $0.6 \mathrm{ml}$ of a 0.1 mol/l taurocholate solution into the pancreatic duct. Over $90 \%$ of control animals died within the first 48 hours after the onset of the pancreatitis $(n=18)$ tions. The addition of camostate $(0 \cdot 1 \mathrm{mg} / \mathrm{ml})$ did not affect amylase activity in the blood when compared with the effect of lavage alone. The results are summarised in Table II.

\section{HISTOLOGY}

The histological changes 12 hours after the onset of pancreatitis were reduced by adding camostate to the lavage fluid. The grading of specific morphological changes of pancreatitis indicated a slightly reduced leucocyte infiltration and extent of necrosis. No changes were noted, however, in the degree of interstitial oedema and cytoplasmic vacuolisation by the addition of camostate compared with lavage alone ( $n=9$ for each group). The results of the histological grading of specific changes in the pancreas are summarised in Table II.

\section{Discussion}

Despite all the efforts to treat acute pancreatitis the mortality is still high. With the exception of intensive care no specific treatment for severe acute pancreatitis has been proved effective in a controlled clinical multicentre study. ${ }^{7}$ Although peritoneal lavage improves the mortality of experimental pancreatitis in dogs, rats, and guinea pigs, ${ }^{8-11}$ studies in humans have not shown a significant improvement in survival with this treatment. ${ }^{1213}$ None of the studies published so far, however, have had sufficient statistical power (1- $\beta$ error) to give confidence in the negative results. ${ }^{\prime}$

Recently it was proposed that peritoneal lavage with the addition of a low molecular weight protease inhibitor should be tested in a clinical trial. ${ }^{3}$ The experimental data which support this suggestion, however, are hardly convincing for a commitment to a clinical study. The study did not show a significant increase in survival rate when comparing the effect of lavage with the addition of a protease inhibitor to lavage alone, although the treatment groups were fairly large. The study evaluated only the effect of one

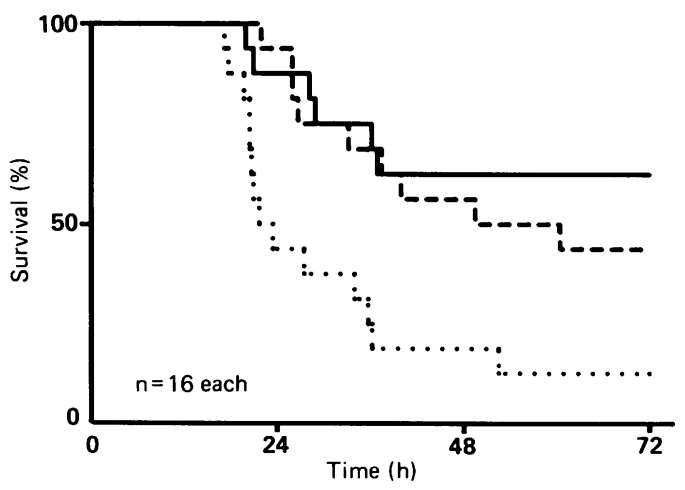

Figure 3: Additive effect of peritoneal lavage during treatment with intravenous camostate in taurocholate induced

pancreatitis in rats. Lavage (group 2) and lavage with camostate (group 3 ) induced a further significant improvement in survival rate when compared to intravenous camostate treatment alone (group $2 \mathrm{v}$ group $1 p<0 \cdot 05$, group $3 \mathrm{v}$ group 1 $p<0 \cdot 01)$. Dotted line $=$ group $1:$ intravenous camostate $(2 \cdot 5$ $\mathrm{mg} / \mathrm{kg}$ per hour), but no lavage, $n=16$. Broken line $=$ group 2 : lavage without addition of camostate to the lavage fluid $(0 \cdot 1$ $\mathrm{mg} / \mathrm{ml}$ ) plus intravenous camostate ( $2.5 \mathrm{mg} / \mathrm{kg}$ per hour), $n=16$. Solid line = group 3: lavage with camostate $(0 \cdot 1 \mathrm{mg} /$ $\mathrm{ml}$ ) plus intravenous camostate $(2 \cdot 5 \mathrm{mg} / \mathrm{kg}$ per hour, $n=16$. 
dose of gabexate mesilate on pancreatitis induced by a choline deficient diet supplemented with ethionine. Gabexate mesilate is a chemically labile ester which is rapidly decomposed and is not effective when administered orally. ${ }^{4}$

The present study investigated the effect of camostate (FOY-305). Camostate has a longer half life than gabexate mesilate and decomposes into a metabolite of camostate (FOY-251) which also inhibits trypsin. ${ }^{4}$

Treatment with camostate was started between seven and nine minutes after the induction of pancreatitis because it is known that in the taurocholate pancreatitis model - unlike in human pancreatitis which takes several hours to develop - five minutes after the injection of bile into the pancreatic duct all the signs of acute pancreatitis are present: oedema and pancreatic necrosis, raised serum amylase activity, and decreased pancreatic enzyme content. ${ }^{14}$

The injection of $0.6 \mathrm{ml}$ of a $0.1 \mathrm{~mol} / 1(5 \%)$ solution of sodium taurocholate into the pancreatic duct induces a severe, haemorrhagic, and necrotising pancreatitis, and the mortality is known to be high: in our study over $90 \%$ of untreated control animals died within the first 48 hours after the induction of pancreatitis (Fig 2) and the survival rates for animals treated with intravenous camostate only ( $12 \%$ at 72 hours) corresponded to those previously published. ${ }^{4}$ This exceptionally severe form of an experimental pancreatitis was chosen because the corresponding indication for the treatment under investigation would be a severe, life threatening pancreatitis in humans.

Taurocholate pancreatitis was thought to be resistant to treatment until it was found recently that intravenous camostate induced a slight, but significant, increased survival time. ${ }^{4}$ The present study shows for the first time a significantly improved survival rate when peritoneal lavage is performed with the addition of camostate to the lavage fluid. The survival rates achieved by the treatment described have not been shown for any other treatment of taurocholate pancreatitis. Peritoneal lavage and simultaneous treatment with intravenous camostate further improves survival (Fig $3, p<0.01$ ), even when the highest possible concentration $(2.5 \mathrm{mg} / \mathrm{kg}$ according to Lankisch $\left.e a^{4}\right)$ is given intravenously.

Peritoneal lavage with camostate added to the lavage fluid resulted in a significantly improved metabolic status, although the severity of the pancreatitis estimated by amylase activity in plasma was not affected, when compared to the effect of lavage alone. The histological degree of the pancreatitis was only slightly improved and the degree of necrosis and vacuolisation corresponded to that found by Niederau et al. ${ }^{3}$ The beneficial effect of lavage with camostate is apparently not associated with an improvement in the severity of pancreatitis as estimated by histology and amylase activity in blood plasma. The improvement in survival by the protease inhibitor camostate therefore might be mediated by systemic effects. Reduction of acidosis may be one of them. Further studies are needed to show that the addition of camostate further improves the therapeutic benefit of peritoneal lavage when camostate is added and the lavage protocol includes frequent input and outflow periods with a short break in between. This might be of particular interest because peritoneal lavage sometimes causes deterioration in respiratory and metabolic function because of the additional volume and patients experience discomfort in the abdominal cavity, particularly those in intensive care requiring artificial ventilation. ${ }^{15}$

Further assessment of the clinical value of peritoneal lavage is needed because the present study has also shown that intravenous camostate and peritoneal lavage with the addition of camostate have an additive effect on survival rate.

We thank J Otto for her help in performing the lavage experiments and for enzyme determinations. This work was supported by the Deutsche Forschungsgemeinschaft, Sonderforschungsbereich 330, Projekt D4.

1 Steinberg WM, Schlesselman SE. Treatment of acute pancreatitis. Comparison of animal and human studies. Gastroenterology 1987; 93: 1420-7.

2 Harrison. Principles of intermal medicine. New York: McGrawHill, 1987: 1375

3 Niederau C, Crass RA, Silver G, Ferrell LD, Grendell JH. Therapeutic regimens in acute experimental hemorrhagic pancreatitis. Effects of hydration, oxygenation, peritoneal lavage and a potent protease inhibitor. Gastroenterology 1988; 95: 1648-57.

4 Lankisch PG, Pohl U, Göke B, et al. Effect of FOY-305 (Camostate) on severe acute pancreatitis in two experimenta (Camostate) on severe acute pancreatitis in two exper

5 Wereszczynska-Siemiatkowska U, Nebendahl K, Pohl U, et Wereszczynska-Siemiatkowska U, Nebendahl $\mathrm{K}$, Pohl U, et
al. Influence of buprenorphine on acute experimental pancreatitis. Res ExpMed 1987; 187: 211-6.

6 Rick W, Stegbauer HP. Alpha-Amylase: Messung der reduzierenden Gruppen. In: Methoden der enzymatischen analyse. Weinheim: Verlag Chemie, 1970: 848-53

7 Creutzfeldt W. Pathogenesis of pancreatitis, the rationale for its treatment by inhibitors of enzyme activity and secretion. Biomed Res 1989; (suppl 1) 10: 15-24.

8 Lankisch PG, Koop H, Winckler K, et al. Continuous peritoneal dialysis as treatment of acute pancreatitis in the rat. Dig Dis Sci 1979; 24: 111-6.

9 Rosato EF, Chu WH, Mullen JL, et al. Peritoneal lavage treatment of experimental pancreatitis. F Surg Reg 1972; 12: $138-40$.

10 Rasmussen BL. Hypothermic peritoneal dialysis in the treatment of acute experimental hemorrhagic pancreatitis. $A m \mathcal{F}$ Surg 1967; 114: 716-21.

11 Rodgers RE, Carey LC. Peritoneal lavage in experimental pancreatitis in dogs. Am $\mathcal{F}$ Surg 1966; 111: 792-4.

2 Mayer AD, McMahon MJ, Corfield AP, et al. Controlled clinical trial of peritoneal lavage for the treatment of severe acute pancreatitis. N Engl f Med 1985; 312: 399-404.

13 Ihse I, Evander A, Holmberg JT, Gustafson I. Influence of peritoneal lavage on objective prognostic signs in acute pancreatitis. Ann Surg 1986; 204: $122-7$.

14 Lankisch PG, Pohl U, Otto J, Rahlf G. When should treatment of acute pancreatitis be started? The early phase of treatment of acute pancreatitis be started? The early phase of

15 Lankisch PG. Peritoneal lavage in the treatment of acute pancreatitis. In: Banks PA, Bianchi G, eds. Acute panpancreatitis. In: Banks $\mathrm{PA}$, Bianchi $\mathrm{G}$, eds. Acute pan-
creatitis. Advances in pathogenesis, diagnosis and treatment. Milano: Masson Italia Editore, 1984: 115-22. 